\title{
Breastfeeding and diversification attitudes among Romanian mothers
}

\author{
Anastasia Simion ${ }^{*}$, Maria Simion², Geanina Moldovan³ \\ 1. County Emergency Clinical Hospital Targu Mures, Romania \\ 2. George Emil Palade University of Medicine, Pharmacy, Science, and Technology of Targu Mures, Romania \\ 3. Department of Community Nutrition and Food Safety, George Emil Palade University of Medicine, Pharmacy, Science, and Technology of Targu Mures, \\ Romania
}

\begin{abstract}
Introduction: Recommended by the World Health Organization as the optimal way of infant feeding, maternal breast milk represents the best nourishment for the newborn baby during its first six months. The purpose of this study was to evaluate some of the Romanian mothers' characteristics that can influence their attitude towards breastfeeding and food diversification. Methods: A questionnaire about 32 questions, including demographics items and breastfeeding attitudes, was sent online (socializing platforms) in 2020 to mothers from all Romania districts. Our sample included at the end 1768 subjects, who fully completed the questionnaire. Statistical analysis was carried out using the GraphPad statistical software. Results: The prevalence of breastfeeding for more than six months was only $32.18 \%$ in our group, and most of them were educated mothers who lives in urban areas $(\mathrm{OR}=2.76)$, were married $(\mathrm{OR}=1.98)$, had over 30 years old $(\mathrm{OR}=1.43)$ and have more than one child $(\mathrm{OR}=1.74)$. Conclusions: We underline the importance of tackling in our future community interventions some of the socio-demographic characteristics of pregnant women (like groups education, good and accessible information about breastfeeding, young age, first pregnancy, or mothers from rural areas as well) in developing good habits of breastfeeding or complementary feeding, in order to improve their children health status and proper development.
\end{abstract}

Keywords: breastfeeding, diversification, nutrition, infant

Received 1 September 2021 / Accepted 14 September 2021

\section{Introduction}

Every year, 2.7 million child deaths are associated with malnutrition, and about $45 \%$ of all deaths involving children are caused by the lack of the essential nutritional factors required for the child to grow healthy. A well-developed nourishment in the first two years of a child's life is a good way to increase their survival, to promote a healthy lifestyle through childhood, and to reduce the risk and prevalence for acute and chronic diseases. [1]. The American Academy of Pediatrics (AAP) highly recommends for babies to be fed exclusively with breast milk for up to six months, and after that to combine breastfeeding with correct diversification for one year or longer [2].

Around the age of six months old, babies start growing faster and therefore need more energy and nutrients than before. Of course, breastmilk continues to be a vital source of nutrition, but it's not enough by itself to meet those needs. Specialists say that introducing solid foods, sometimes called complementary feeding or weaning, should start around this time of age [3].

When diversification starts late, after six months, and complementary foods are given inadequately, the child's development could suffer significant issues [4]. Both, lack of breastfeeding, and an ineffective diversification comes with important disadvantages for the child. Therefore, a proper nutrition turns out to be a decisional factor in decreasing the level of chronic diseases.

* Correspondence to: Anastasia Simion

E-mail: simion.anastasia@yahoo.com
The purpose of this study was to evaluate some of the Romanian mothers' characteristics that can influence their attitude towards breastfeeding and food diversification, like demographics variables (age, residence, education, marital status, or size of the family).

\section{Material and method}

In order to collect data, a questionnaire made from 32 questions, was sent online in January 2020 to mothers from all Romanian districts, containing questions about socio-demographic aspects and attitudes to breastfeeding and diversification. The mothers were informed from the beginning that the questionnaire is anonymous and the data collected will not be used for any other purpose, and we have their consent.

The questionnaire was divided into 2 parts: the first part assessed personal and socio-demographic factors such as age of the mother, education level, place of origin, marital status and number of the children. In the second part of the questionnaire (questions from 12 to 32), information about breastfeeding and diversification were the main interest. The mothers were asked to choose one or more of the given options, as to respond to some open questions as well. The answers were grouped into specific categories.

A total number of 1796 filled in questionnaires were received, from which 1768 remained valid for analysis, due incomplete answers that were used as exclusion criteria.

Our sample was divided in 4 categories: based on age ( $\leq$ 30 years old, and $>30$ years old), and the number of children (one, and more than one). 
Answers of the following questions were adjusted into 5 variables:

- level of education (primary and secondary education/ tertiary education);

- residency (urban/ rural);

- marital status (married/ unmarried);

- the infant age until mothers breastfed (less than six months/ more than six months);

- the age at which mothers began to diversify infant diet (before six months old/ later than six months).

Statistical analysis was carried out using GraphPad, Fisher's test. Rejection of the null hypothesis was based on the following levels of significance: $\mathrm{p}$ value $=0.05(<0.05-$ significant, $<0.01$ - highly significant).

\section{Results}

Our sample was represented in detail, related to age and number of children, to be seen in Table I.

In order to study the socio-demographic factors impact upon breastfeeding we split our sample in 2 groups, related to age (presented in Table II).

Based on age variable, we found out that were statistical differences between younger and older mothers regarding their level of education $(\mathrm{p}<0.0001)$, living environment $(\mathrm{p}<0.0001)$ and number of children $(\mathrm{p}<0.0001)$. Younger mothers who answered to our questionnaire have a lower level of education $(\mathrm{OR}=2.14)$, live mostly in urban areas $(\mathrm{OR}=2.20)$, and tend to have more than one child $(\mathrm{OR}=2.36)$. There were no significant differences between mothers regarding age and marital status $(\mathrm{p}=0.85)$.

Analyzing socio-demographic factors and the number of children (one versus more than one) statistically significant associations were obtained in relation to: level of education $(\mathrm{p}<0.0001)$ and marital status $(\mathrm{p}<0.0001)$ - mothers with more than one child have finished tertiary education $(\mathrm{OR}=4.73)$, and are married $(\mathrm{OR}=2.60)$. No significant association was identified between the number of children and living environment $(\mathrm{p}=0.41)$.

Regarding the socio-demographic factors, other than the age of mothers or the number of children, significant associations were found between the level of education and the living environment $(\mathrm{p}<0.0001)$, and the level of education and marital status $(\mathrm{p}=0.0002)$, with a higher prevalence of educated mothers who live in urban areas $(\mathrm{OR}=2.76)$ and are married $(\mathrm{OR}=1.98)$. No significant differences were found between living environment and marital status $(\mathrm{p}=0.34)$.

In order to assess whether the age of the mothers and the number of children influences the age until mothers breastfed or the age at which mothers begin the complementary feeding, Fisher's exact test was applied. The re- sults were similar in both categories: the age until mothers breastfed differed significantly when taking into consideration the age of the mothers $(\mathrm{p}=0.0012)$ and the number of children $(p<0.0001)$ - meaning that the mothers who breastfed for more than six months are the ones older than 30 years old $(\mathrm{OR}=1.43)$, and the ones with more than one child $(\mathrm{OR}=1.74)$. Concerning the age of which mothers began to wean, no significant association was found in either the age of the mothers $(\mathrm{p}=0.31)$ or the number of children $(\mathrm{p}=0.10)$.

From the total number of respondents, $32.18 \%$ of mothers $(\mathrm{n}=569)$ were found to exclusively breastfeed for up to six months: $391(68.71 \%)$ from urban areas and 438 $(78.97 \%)$ with higher education.

\section{Discussions}

Our research attempted to bring into discussion Romanian mother's choices in breastfeeding and diversification, in relation to their environmental status. As expected, there are associations statistically significant between breastfeeding attitudes and socio-demographic factors (like mothers age, family members, marital status, residency end education level). It is well known that feeding a baby in the first year after birth is an exciting adventure for both, parents and baby. It is about development, nutrition, curiosity, sharing and learning. Children can develop a lifetime of healthy eating habits if they receive appropriate guidance from the beginning.

In the light of our results, which showed an increased number of mothers with higher education, married and who lives in urban areas that are breastfeeding, similar studies revealed the importance of socio-demographic fac-

Tabel II. Connections between socio-demographic variables, mothers age and number of children in the family

\begin{tabular}{lccc}
\hline Socio-demographic variables & $\begin{array}{c}\text { Young } \\
\text { moms } \\
\text { (no=864) }\end{array}$ & $\begin{array}{c}\text { Older } \\
\text { moms } \\
\text { (no=904) }\end{array}$ & p \\
\hline Breastfeeding & 483 & 589 & $\mathrm{p}=0.0012$ \\
$\quad$ - more than 6 months & 251 & 213 & \\
- less than 6 months & & & \\
\hline Diet diversification & 260 & 253 & $\mathrm{p}=0.3190$ \\
- before 6 months & 595 & 643 & \\
- after 6 months & & & \\
Number of children & 597 & 396 & $\mathrm{p}<0.0001$ \\
- one child & 267 & 508 & \\
- more than one child & & & \\
\hline Level of education & 363 & 228 & $\mathrm{p}<0.0001$ \\
- primary and secondary education & 501 & 676 & \\
- tertiary education & & & \\
Residency & 508 & 686 & $\mathrm{p}<0.0001$ \\
- urban & 356 & 218 & \\
- rural & & & \\
\hline Marital status & 799 & 833 & $\mathrm{p}=0.8584$ \\
- married & 65 & 71 & \\
- unmarried & & & \\
\hline
\end{tabular}

Tabel I. Frequency of mothers related to the age and number of children variables

\begin{tabular}{llll}
\hline Groups based on age & & Groups based on the number of children \\
\hline Mothers younger than 30 years old & $864(48.86 \%)$ & Mothers with one child & $993(56.16 \%)$ \\
Mothers older than 30 years old & $904(51.13 \%)$ & Mothers with more than one child & $775(43.83 \%)$ \\
\hline
\end{tabular}


tors in mother's choices of breastfeeding and diversification as well [5-7].

In our study, mothers who exclusively breastfed for six months represented approximatively one third of the questioned group. In Romania, the rate of exclusive breastfeeding of the baby up to six months is an increasing trend, from $12.6 \%$ in 2011 to $29.8 \%$ in 2016 , as presented in a study conducted by SAMAS association [6]. The statistics showed no significant association between diversification and the age of the mothers or number of children, but the total number of mothers who started diversification at the age of six months is more than $70 \%$ which proves that mothers are well informed about diversification.

There are several studies that show the importance of complementary feeding and the age when it is introduced $[8,9]$. Therefore, it is important for mothers to understand that during the first years of life, high-quality feeding interactions tend to be positively linked to the child's subsequent cognitive and linguistic competence and to more secure attachments to major caregivers [10].

A limitation of our study is that the feeding behaviors were self-reported. More educated mothers may be more aware of socially expected responses (regardless of their actual behavior), or if they report less expected responses, they may be afraid of being stigmatized, which exaggerates the differences between different educational groups. However, this is a limitation common to most studies.

\section{Conclusions}

The age, number of children, level of education, the marital status and the living environment were directly associated with mothers' attitudes toward breastfeeding, and this shows the importance of socio-demographic factors in developing good habits of breastfeeding or complementary feeding.

Our study underlines the importance of tackling in our future community interventions some of the socio-demographic characteristics of pregnant women (like groups education, good and accessible information about breastfeeding, young age, first pregnancy, or mothers from rural areas as well) in developing good habits of breastfeeding or complementary feeding starting after birth, in order to improve their children health status and proper development.

\section{Authors' contribution}

AS (Conceptualization; Data curation; Project administration; Software; Writing - original draft; Writing - review \& editing)

MS (Resources; Formal Analysis; Writing - original draft; Writing - review \& editing)

GM (Methodology; Project administration; Supervision; Validation; Visualization)

\section{References}

1. Infant and young child feeding [Internet]. [cited 2021 Jul 25]. Available from: https://www.who.int/news-room/fact-sheets/detail/infant-andyoung-child-feeding

2. Breastfeeding SO. Breastfeeding and the Use of Human Milk. Pediatrics. 2012 Mar 1;129(3):e827-41.

3. Feeding your baby: 6-12 months | UNICEF Parenting [Internet]. [cited 2021 Jul 25]. Available from: https://www.unicef.org/parenting/foodnutrition/feeding-your-baby-6-12-months

4. Agostoni C, Decsi T, Fewtrell M, Goulet O, Kolacek S, Koletzko B, et al. Complementary feeding: a commentary by the ESPGHAN Committee on Nutrition. J Pediatr Gastroenterol Nutr. 2008 Jan;46(1):99-110.

5. Prickett KC, Augustine JM. Maternal Education and Investments in Children's Health. J Marriage Fam. 2016 Feb;78(1):7-25.

6. Studiul SAMAS 2016 privind alăptarea și nutriția copilului mic - SAMAS : SAMAS [Internet]. [cited 2021 Aug 19]. Available from: https://www. programsamas.ro/studiul-samas-privind-alaptarea-si-diversificareacopilului-mic-2016/

7. Islam A, Islam N, Bharati P, Aik S, Hossain G. Socio-economic and demographic factors influencing nutritional status among early childbearing young mothers in Bangladesh. BMC Womens Health. 2016 Aug 26;16(1):58.

8. Agostoni C, Decsi T, Fewtrell M, Goulet O, Kolacek S, Koletzko B, et al. Complementary feeding: a commentary by the ESPGHAN Committee on Nutrition. J Pediatr Gastroenterol Nutr. 2008 Jan;46(1):99-110.

9. Silva Al, Aguiar HG. [Diversification in the first year of food life]. Acta Med Port. 2011 Dec;24 Suppl 4:1035-40.

10. Wallis AB, Brînzaniuc A, Cherecheș R, Oprescu F, Sirlincan E, David I, et al. Reliability and validity of the Romanian version of a scale to measure infant feeding attitudes and knowledge. Acta Paediatr Oslo Nor 1992. 2008 Sep;97(9):1194-9. 